\title{
Developing Master Curves, Binder Viscosity and Predicting Dynamic Modulus of Polymer-Modified Asphalt Mixtures
}

\author{
Ainalem Nega, Behzad Ghadimi, and Hamid Nikraz
}

\begin{abstract}
The complex moduli relationship related mixture moduli to temperature and time rate of loading has been an integral part of several mechanistic-empirical (M-E) design procedures used throughout of the world. Seven asphalt concrete mixtures of different types of polymer modified binders (PMB) were produced in a laboratory to modify performance of asphalt mixture. The main role of this research is to evaluate the influence of these polymer modifiers on the pavement performance of asphalt mixture with the dynamic modulus, $\left|E^{*}\right|$ of hot-mix asphalt (HMA) mixture indicator in a laboratory test for Mainroad Western Australia and Fulton Hogan. In this study, the influence of temperature, loading frequency, and confining pressure on the dynamic characteristic of asphalt mixture were analysis, master curves of dynamic modulus of HMA mixtures were developed and data's were interpreted. Results showed that AC10 5.7\% A35P (EVA) M7 B5, AC10 5.7\% C450 M10 B5 and AC10 Multi 600/700 M5 B4 mixes method were the more efficient and effective in all categories of asphalt performance measures for strength and durability of HMA as compared to others polymer modifiers. A very good correlation $\left(R^{2}=1\right)$ was found for each polymer modifier. This suggested that laboratory test using a various temperatures and loading frequencies can improve pavement mix design, lab and field control and assurance. A strong correlation between binder viscosity and temperature $\left[R^{2}=1\right]$ for polymer modified asphalt mixture.
\end{abstract}

Index Terms-Polymer modifier, dynamic modulus, master curve; viscosity, temperature, asphalt mixture, western Australia.

\section{INTRODUCTION}

The new American Association of State Highway and Transportation Officials (AASHTO) Mechanistic-Empirical Pavement Design Guide (MEPDG) based on the National Cooperative Highway Research Program (NCHRP) 1-37A study uses the dynamic modulus of asphalt mixture, $\left|E^{*}\right|$, as the asphalt material input in its pavement analysis [1], [2]. The concept of a dynamic modulus protocol was originally developed by Coffman and Pagen at Ohio State University in the 1960s [3] and this test was not implemented for payment design and analysis until recently [4]. The test can be applied in a uniaxial (triaxial) condition either compression or

Manuscript received April 3, 2014; revised June 8, 2014. This work was supported by Australia Government under Australia Postgraduate Award (APA) grant and Curtin University under Curtin Research Scholarship (CRS) award.

The authors are with the Department of Civil Engineering, Curtin University, GPO Box U1987, Perth, WA 6845, Australia (e-mail: Ainalem.Nega@curtin.edu.au,_Behzad.Ghadimi@curtin.edu.au, H.Nikraz@curtin.edu.au) tension. Most of the test results obtained over the past 30 years have been in compression and are generally denoted as $E^{*}$. The $E^{*}$ test was adopted as the "Modulus Test of Choice" by the Asphalt Institute in the late 1960s by Kallas, Shook and Witczak [3]. It subsequently became an American Society of Testing and Materials (ASTM) standard in early 1970 under ASTM designation D3496 [5].

The dynamic modulus of hot-mix asphalt (HMA) is an important input parameter in asphalt pavement design. The mechanistic-empirical pavement design guide (MEPDG) recommends determining dynamic modulus at three levels: Level 1, Level 2, and Level 3 of analysis for predicting the performance of flexible pavement as discussed by NCHRP [2]. The use of a particular hierarchal input Level 1 of analysis depends on the amount of information available to the designer and the critically of the project. For example, at Level 1, the asphalt binder and the HMA are tested in the laboratory to measure dynamic modulus. However, the measurement of dynamic modulus in the laboratory is not always feasible because of the tedious experiments and it may also take several days to develop a single master curve [6]-[8].

To overcome these difficult, the MEPDG recommends estimating the dynamic modulus without conducting actual modulus tests in the laboratory for Level 2 and Level 3 design [8]. Several prediction models are available in the literature for estimating the dynamic modulus of HMA. These models use the volumetric properties of mix, aggregate graduation, loading frequency and viscosity of an asphalt binder to predict dynamics as discussed on literature by [8]-[13]

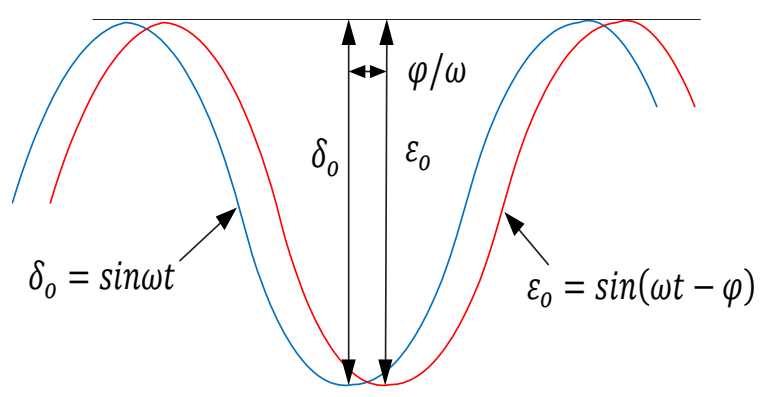

Fig. 1. Dynamic (complex) modulus.

Dynamic modulus testing characterizes asphalt mixture as a linear viscos-elastic material over a wide range of temperature and loading frequency. In the MEPDG, dynamic modulus testing results are used to generate a master curve for each mixture by the time-temperature superposition methodology [2]-[4]. The dynamic modulus is a fundamental asphalt mixture property and it can be used to investigate the 
temperature and loading frequency of hot-mix asphalt pavement because of its main application MEPDG in the form of a master curve.

The goal of this study is to evaluate the influence of polymer modified binders (PMB) on the pavement performance of asphalt mixtures for Western Australia Main Roads. Results from this research will be of great guidance in selecting modifier material for Western Australia.

\section{METHODS AND MATERIALS}

\section{A. Methods}

For linear visco-elastic material such as HMA mixture, the stress-strain relationship under a continuous sinusoidal loading is defined as by its complex dynamic modulus $\left(E^{*}\right)$. This is a complex number that relates stress to strain for linear visco-elastic material subjected to continuously applied sinusoidal loading in frequency domain [3]. The complex modulus is defined as the ratio of the amplitudes of the sinusoidal stress at any given time, $t$ and angular loading frequency, $\omega, \delta=\delta_{0} \sin (\omega t)$ and the amplitude of sinusoidal strain, $\phi=\delta_{\mathrm{o}} \sin (\omega t-\phi)$, at the same time and frequency, that result in the steady response is shown in Fig. 1.

The dynamic (complex) modulus equation can mathematically be expressed as:

$$
E^{*}=\frac{\delta}{\varepsilon}=\frac{\delta_{0} e^{i \omega t}}{\varepsilon_{0} e^{i(\omega t-\varphi)}}=\frac{\delta_{0} \sin \omega t}{\varepsilon_{0} \sin (\omega t-\varphi)}
$$

where, $\delta_{0}$ peak (maximum) stress; $\varepsilon_{0}$ peak (maximum) strain; $\phi=$ phase angle degree; $\omega=$ angular velocity; $i=$ imaginary component of the complex modulus and $t=$ time. Mathematically, the dynamic modulus is defined as the absolute values of the complex modulus and the equation (1) can be written as

$$
\left|E^{*}\right|=\frac{\delta_{0}}{\varepsilon_{0}}
$$

The primary output variable of the test is the dynamic modulus $\left|E^{*}\right|$ and the phase angle $(\phi)$, which is a direct indicator of the elastic-viscous properties of the mix or binder material. The dynamic modulus in the compression $\left|E^{*}\right|$ of the mix is similar in principle to the $G^{*}$ complex shear modulus of the binder developed in the SHRP and SuperPave programs at the University of California, Berkley, and Penn State University [3]. The two moduli, $E^{*}$ and $G^{*}$ are theoretically related through engineering mechanics by the relationships:

$$
E^{*}=2(1+\mu) G^{*}
$$

In the proposed "2002 Guide for the Design of Pavement System", currently under development in NCHRP project
1-37A, the modulus of the asphalt concrete-at all analysis level of temperature and time rate of load-is determined from the a master curve constructed at a reference temperature, generally $21.1^{\circ} \mathrm{C}(70 \mathrm{~F})$ [2], [3], [14]-[16]. Master curves are constructed using the principle of time-temperature superposition. The data at various temperatures should be shifted with respected to log of time until the curves merge in to a single smooth function. The resulting master curve of the modulus, as a function of time, formed in this manner describes the time depending of the material [3]. The amount of shift required at each temperature to form the master curve describes the temperature depending of the material. In general, the master modulus curve can be mathematically modeled by a sigmoidal function described as:

$$
\log \left|E^{*}\right|=\frac{\delta+\alpha}{1+e^{\beta+\gamma\left(\log t_{r}\right)}}
$$

where, $t_{r}=$ time of loading at reference temperature; $\delta=$ minimum value of $E^{*} ; \delta+\alpha$ maximum value of sigmoidal; $\beta, \gamma=$ parameters describing the shape of sigmoidal function; and $\alpha$ variable which is function of gradation. The shift factor can be shown in the following form:

$$
\alpha(T)=\frac{t}{t_{r}}
$$

where, $\alpha(T)$ shift factor as a function of temperature; $t=$ time of loading during test, $s ; t_{r}$ time of loading at reference usually $\left(70{ }^{\circ} \mathrm{C}\right)$ and $T=$ temperature of loading cycle. The equation can be re-arranged in term of the reduced time $\left(t_{r}\right)$ of the loading at the reference temperature as:

$$
\begin{gathered}
t_{r}=\frac{t}{\alpha(T)} \\
t=\frac{1}{2 \pi f}
\end{gathered}
$$

where, $f$ is the loading frequency at desired temperature, Hz. For the sake of accuracy, a second-order polynomial relationship between the logarithm of shift factor, $\log \alpha(T)$ and the temperature is used. The relationship can be expressed as follows:

$$
\begin{gathered}
\alpha(T)=10^{a(T-25)^{2}+b(T-25)} \\
\log \chi\left(T_{i}\right)=a\left(T_{i}-5\right)^{2}+b\left(T_{i}-25\right)
\end{gathered}
$$

where, $\alpha\left(T_{i}\right)$ a shift factor as the function of temperature $T_{i} ; T_{i}$ is temperature of interest; $\mathrm{a}$ and $\mathrm{b}$ are a coefficient of the second-order polynomial. The dynamic modulus, $E^{*} f$ 
the mix and the complex shear modulus of binder, $G^{*}$ relationship that is described in equation (3) can be re-arranged as:

$$
G^{*}=\frac{E^{*}}{2(1+\mu)}
$$

Asphalt technicians have used the viscosity - temperature relationship or viscosity - temperature susceptibility (VTS) method of binder temperature susceptibility classification for decades [17], [18], although it has not been used as a popular index values for this purpose. One basic definition of VTS [19]:

$$
\mathrm{VTS}=\frac{\log \left[\log \left(\eta_{T 2}\right)-\log \left[\log \left(\eta_{T 1}\right)\right]\right.}{\log \left(T_{2}\right)-\log \left(T_{1}\right)}
$$

where, $T_{2}$ and $T_{1}$ is a temperature of the binder at two known points ( $R=$ degree Rankine) and $\eta_{T 2}$ and $\eta_{T 1}$ re viscosities of the binder at the same two point (cp). The larger the magnitude of the VTS value is found to be, the more susceptible the binder is to change in viscosity with temperature. In 1967, Puzinauskas derived the VTS for over 50 binders commonly used in the United States at that time, and found the VTS value to range [based on Eq. (11)] from -3.36 to -.3 .98 [17].

Fonseca and Witczak [20] presented a new model for prediction of the dynamic modulus of hot-mix asphalt (HMA) that included the binder viscosity as an input variable. The model include a calculation of methods for binder viscosity at a function of temperature and age [19]. These formulations were based on the VTS formula, as well as a second parameter, A. The ' $A$ ' parameter is the $\mathrm{y}-$ axis intercept of the $\log [\log$ (viscosity) $]$ and $\log$ (temperature) curves. The A parameter cannot be measure directly, but it can be derived from least - squares fit of viscosity - temperature data from a given binders. The basic formula for viscosity of binder can be described as [3]:

$$
\eta=\frac{\left|G^{*}\right|}{10}\left(\frac{1}{\sin _{\delta_{b}}}\right)^{4.8628}
$$

The basic formula for VTS and A is:

$$
\log [\log (\eta)]=A+V T S \times \log \left(T_{R}\right)
$$

where $\phi$ is viscosity of binder, (cp); $\left|G^{*}\right|$ s complex shear modulus of binder, $\mathrm{Pa} ; \delta_{b}$ s phase angle of binder associate with $\left|G^{*}\right|$ degree; A is binder (intercept) parameter and VTS is slope parameter and $T_{R} \mathrm{~s}$ temperature, ${ }^{\circ}$ Rankine.

\section{B. Materials}

Types of hot-mix asphalt used on the Mainroads Western Australia network are dense graded asphalt (DGA), open graded asphalt (OGA) and stone mastic asphalt (SMA). DGA, the most common type of asphalt, provides optimal structure strength and generally good resistance to deformation. OGA is designed to drain water through the asphalt to remove excess water from the tyre/road surface. SMA is similar to OGA but has a high proportion of dust and high binder contents to achieve an improved fatigue life. SMA has a texture surface but does not drain water through its layer as does OGA [21]-[23]. All Materials selected for this project were from local sources and are originally of Western Australian pavement materials used in the industry.

In order to assess the master curve development and predict the dynamic modulus of polymer modified of hot-mix asphalt mixture, it is necessary to obtain laboratory data of different types of modifiers and characteristic of asphalt mixes. The properties of asphalt AH-70 Grade are listed on Table I. Seven modifiers were selected for this study and the mixes descriptions for developing master curves and predicting dynamic modulus of polymer modified asphalt mixtures were: C320 M1 B3; A10E M2 B4; A15E M3 B4; Multi 600/170 M5 B4; A20E M6 B7; A35P (EVA) M7 B5; and $\mathrm{C} 450 \mathrm{M} 10 \mathrm{~B} 5$. Each asphalt mixture consists $10 \mathrm{~mm}$ dense graded granite (AC10) and binder of 5.7 percent.

TABLE I: PROPERTIES OF ASPHALT AH-70 GRADE

\begin{tabular}{|l|r|}
\hline Mix Design Properties & Specification Value \\
\hline Penetration $\left(25^{\circ} \mathrm{C}, 100 \mathrm{~g}, 5 \mathrm{~s}, 0.1 \mathrm{~mm}\right)$ & 160.00 \\
\hline Ductility $\left(5 \mathrm{~cm} / \mathrm{min}, 15^{\circ} \mathrm{C}\right)$ & 52.40 \\
\hline Softening $($ ring and ball method) & 1.04 \\
\hline Density $\left(\mathrm{g} / \mathrm{cm}^{3}, 15^{\circ} \mathrm{C}\right)$ & 270.00 \\
\hline Flash point $\left({ }^{\circ} \mathrm{C}\right)$ & 2.10 \\
\hline Wax content $(\%)$ & 99.70 \\
\hline Solubility $(\%)$ & Negative \\
\hline Spot test & \\
\hline
\end{tabular}

\section{Specimen Preparation and Compaction of Mixes}

Sample preparation and compaction temperature were obtained to each asphalt mixes using consistence test results according Australian Standard Test Methods: AS2891 and AS2150. The hot-mix asphalt (HMA) mixtures were heated for $2 \mathrm{hr}$ at $170{ }^{\circ} \mathrm{C}$ in oven before compaction. The Gyratory compaction pressure was $600 \mathrm{kPa}$. The test sample was then compacted with gyratory compaction using the Servopac into $150 \mathrm{~mm}$ diameter $170 \mathrm{~mm}$ in height. The Servopac is a fully automated, servo-controlled, gyratory compactor designed to compact asphalt mixes by gyratory compaction. Compaction is achieved by the simultaneous actions of static compression and the shearing action resulting from the mould being gyrated through an angle about its longitudinal axis. Test specimen was cored from the center of the gyratory compacted sample. The specimen was sawn at approximately $5 \mathrm{~mm}$ from each sample to have the final $110 \mathrm{~mm}$ diameter $\mathrm{x}$ $160 \mathrm{~mm}$ height of $E^{*}$ test specimen. All the test specimens were compacted to about $5 \%$ air voids. The mix design for AC10 mm dense graded granite is shown in Table II was designed in according with Gyratory volumetric mix design procedures and it optimum asphalt bender content $\left(P_{b}\right)$ is $5.7 \%$, air void is $4 \%$, and void in mineral aggregate (VMA) 
are $17.7 \%$, voids filled with asphalt (VFA) are $75 \%$; and effective binder content $\left(V_{\text {beff }}\right)$ is $12 \%$.

TABLE II: MIX DESIGN FOR AC10 MM DENSE GRADED GRANITE

\begin{tabular}{|c|c|c|c|c|c|c|c|c|c|c|c|}
\hline \multicolumn{12}{|c|}{ Mass percentage passing sieve size } \\
\hline Gradation $(\mathrm{mm})$ & 19.0 & 13.2 & 9.5 & 6.7 & 4.75 & 2.36 & 1.18 & 0.6 & 0.3 & 0.15 & 0.075 \\
\hline Percentage passing by weight & 100 & 91 & 76 & 61 & 48 & 32 & 21 & 15 & 8 & 5 & 3 \\
\hline Austroad Specification limit & 100 & 100 & 100 & $85-100$ & $30-63$ & $20-35$ & $16-28$ & $14-24$ & $12-20$ & $10-16$ & $8-12$ \\
\hline
\end{tabular}

TABLE III: MASTER CURVES AND SHIFT PARAMETERS

\begin{tabular}{|l|l|l|l|l|l|l|l|}
\hline Mix Description & $\delta$ & $a$ & $\beta$ & $\gamma$ & $a$ & $\mathrm{~b}$ & \%V SSD \\
\hline AC10 5.7\% C320 M1 B3 & 0.736754 & 3.557723 & -0.80766 & 0.657819 & 0.000819 & -0.11304 & 5.24 \\
\hline AC10 5.7\% A10E M2 B4 & 1.013825 & 3.160096 & -0.16244 & 0.625139 & 0.000637 & -0.10007 & 4.79 \\
\hline AC10 5.7\% A15E M3 B4 & 0.923342 & 3.309382 & -0.56845 & 0.496263 & 0.000742 & -0.11319 & 6.35 \\
\hline AC10 5.7\% Multi 600/170 M5 B4 & 1.413448 & 2.843524 & -0.37136 & 0.504290 & 0.000723 & -0.10783 & 6.92 \\
\hline AC10 5.7\% A20E M6 B7 & 0.858570 & 3.392841 & -0.30221 & 0.614766 & 0.000801 & -0.10642 & 7.54 \\
\hline AC10 5.7\% A35P (EVA) M7 B5 & 1.387350 & 2.880641 & -0.74875 & 0.573965 & 0.000356 & -0.11132 & 6.84 \\
\hline AC10, 5.7\% C450, M10 B5 & 1.003145 & 3.232011 & -0.77564 & 0.690726 & 0.000374 & -0.10312 & 6.35 \\
\hline
\end{tabular}

TABLE IV: MASTER CURVES OF SEVEn DifFERENT MiXTURES

\begin{tabular}{|l|l|l|l|l|l|l|l|l|}
\hline Mix Description & $\log \operatorname{tr},(\mathrm{s})$ & \multicolumn{7}{|c|}{$\log \left|\mathrm{E}^{*}\right|(\mathrm{MPa})$} \\
\hline C320 M1 B3 & -1.0 & 2.79473 & 2.38442 & 2.74092 & 2.83997 & 2.43913 & 3.05507 & 2.849 \\
\hline A10E M2 B4 & -0.3 & 2.64026 & 2.30052 & 2.6238 & 2.75591 & 2.33331 & 2.91509 & 2.7068 \\
\hline A15E M3 B4 & 0.0 & 2.34737 & 2.09501 & 2.40515 & 2.58353 & 2.11167 & 2.63943 & 2.38452 \\
\hline Multi600/170 M5 B4 & 0.7 & 2.38226 & 2.13106 & 2.4102 & 2.60249 & 2.16821 & 2.55879 & 2.3259 \\
\hline A20E M6 B7 & 1.0 & 2.28145 & 2.0468 & 2.31411 & 2.53373 & 2.10829 & 2.35407 & 2.10125 \\
\hline A35P (EVA) M7 B5 & 1.3 & 2.27536 & 2.01983 & 2.27816 & 2.51481 & 2.12642 & 2.19501 & 1.93154 \\
\hline C450 M10 B5 & 1.4 & 2.24526 & 1.9613 & 2.22218 & 2.47662 & 2.12371 & 2.02297 & 1.71278 \\
\hline
\end{tabular}

\section{Dynamic Modulus}

The dynamic modulus test was conducted using IPC test machine, and is capable of providing a constant pressure upto $210 \mathrm{kPa}$ and an environmental chamber to control testing temperatures (between $-40{ }^{\circ} \mathrm{C}$ and $+90{ }^{\circ} \mathrm{C}$ ). Test specimens were accomplished using gluing gauge plugs onto the side of the specimen and attached a Linear Variable Differential Transducer (LVDT) to the plugs to measure the displacement A haversine loading $\left(P_{\text {dynamic }}\right)$ was adjusted in order to obtained axial strains between 75 and 125 microstrain to the specimen without impact in a cyclic manner. For each asphalt mix, 3 replicates were prepared. Since this paper is mainly focused on mixture performance at high temperature, each specimen in this study was tested at $30,40,50,60,70,80$, and $90{ }^{\circ} \mathrm{C}$ without being at low temperature. The loading frequencies were $0.1,0.5,1,5,10,20$, and $25 \mathrm{~Hz}$, respectively.

\section{RESULTS AND ANALYSIS}

\section{A. Master Curve}

A summary of $\left|E^{*}\right|$ versus loading frequency for different types of polymer modifiers are shown in Fig. 2 As it has shown from the plot, the $\left|E^{*}\right|$ data are shifted using a nonlinear optimization and solve shift parameters. As the result of these seven parameters of master curves, models are fitted by almost least squares methods with matlab program in this study. From the data presented, it can be seen that all the modifiers have the same pattern and linear range to all asphalt mixes although they have a different $\left|E^{*}\right|$ This showed that the stress to strain for linear visco-elastic materials subjected to continuously applied sinusoidal loading in frequency domain at the time and frequency results a steady response and reduce typical dynamic stress level based on the various temperature. Dougan et al., [3] discussed that the dynamic modulus that subjected to continuously applied sinusoidal loading in the frequency domain at the time and frequency results a steady response and reduce a friction at the bottom of the loading frame.

Master curves and shift parameters are listed on Table III. The seven shift parameters which are listed in Table III are then used in (4) in order to calculate the $\left|E^{*}\right|$ of each mix at any given temperature and loading frequency within the same range that are used in the $\left|E^{*}\right|$ testing at reference temperature of $25^{\circ} \mathrm{C}$ following the superposition.

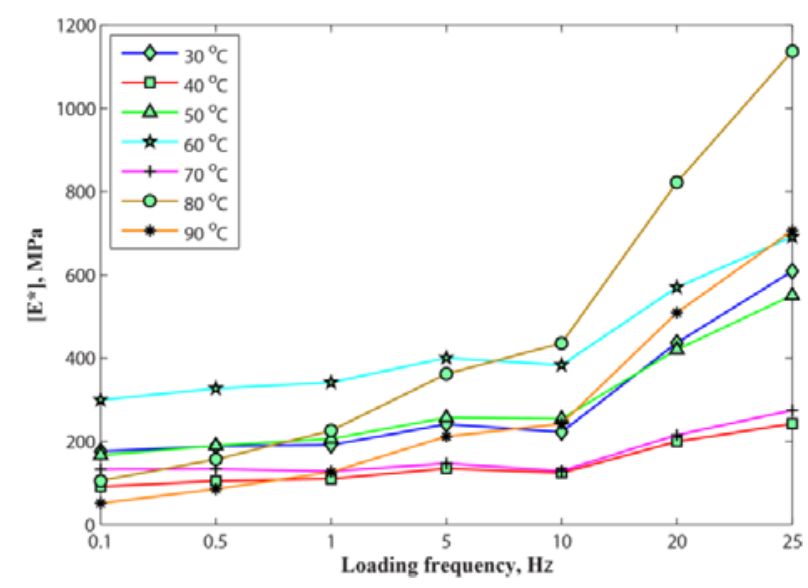

Fig. 2. Plot of loading frequency versus $\left|E^{*}\right|$.

The shift factor $\alpha(T)$ versus temperature is given in Fig. 3. These seven parameters are then used in (4) to calculate $\left|E^{*}\right|$ of the particular asphalt mix at the temperature and 
loading frequency within the range in $\left|E^{*}\right|$ testing. $\left|E^{*}\right|$ master curves of all mixtures were constructed at the reference $25{ }^{\circ} \mathrm{C}$ following the principle time-temperature superposition. The data at various temperatures were shifted in line with frequency until the curves merges into a single sigmoidal function which represent the master curve using a second-order polynomial relationship between the logarithm of the shift factor, $\log \alpha(T)$ and temperature as it is shown in Fig. 3 and very good correlation $\left(R^{2}=1\right)$ between them $E^{*}$ and loading frequency with shift factor as function of temperature. Zhu et al., [24] developed a master curves and predicting dynamic modulus of polymer modified asphalt mixture for four types of polymer modifiers and plotted shift factor $\alpha(T)$ versus temperature with very good correlation $\left[R^{2}=0.9981\right]$.

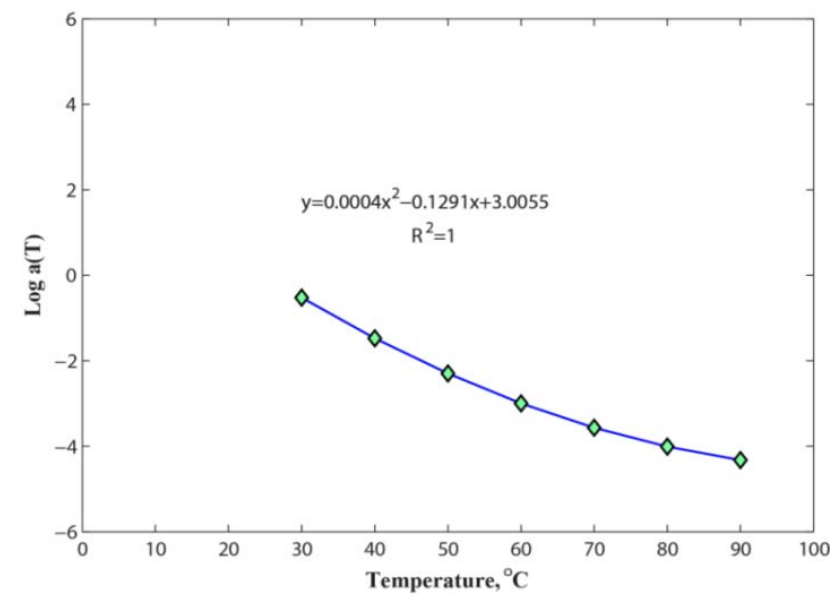

Fig. 3. Plot of shift factor $\alpha(T)$ Versus temperature.

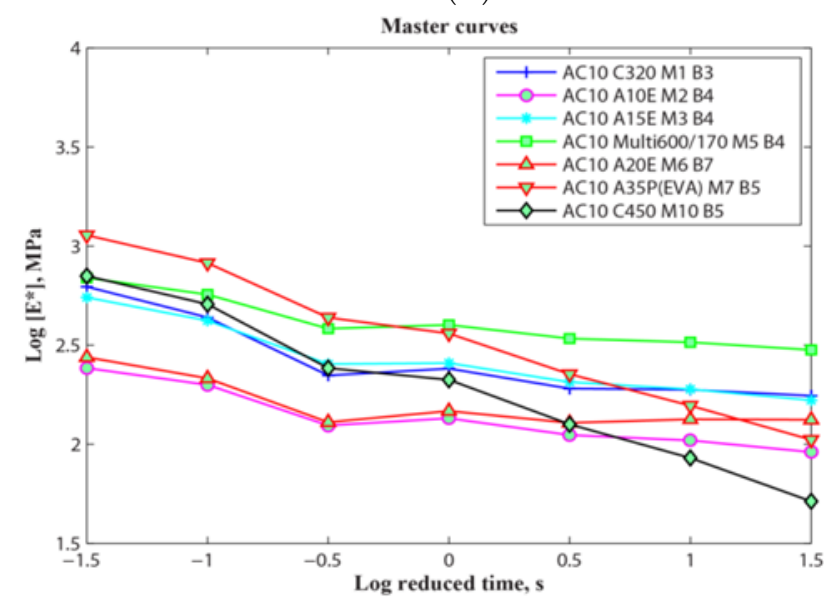

Fig. 4. Master curves of seven different mixtures.

\section{B. Effect of Polymer Modifiers}

On the basis of this research, it is found that different polymer modifiers vary in their influences on the stiffness of mixture. Fig. 4 compares the effect of seven different polymer modifiers on the dynamic modulus $\left|E^{*}\right|$. As it can be seen from plot, each of them has similar results with a similar pattern and a linear range to all. As the result of this, it has only put one figure in order to avoid repeating same figures because of the similarity (refer to Table IV). These showed that the stress dependent asphalt mix master curve using compressive dynamic (complex) modulus test data is in a good correlation with temperature. Pellinen and Witczak [25] analyzed the use of stiffness of hot-mix asphalt using a simple performance test that limit the stiffness value because of the power law and sigmoidal function.

The data at various temperature where shifted in line with frequency until the master curve merges in a single sigmoidal function, representing the master curve using a second-order polynomial relationship between the logarithm of the shift factor and the temperature (Fig. 4). Time-temperature superposition was done by simultaneously solve the four coefficients of sigmoidal function $(\delta, \alpha, \beta$, and $\gamma)$ as described in (4). Equation (8) and (9) defined three coefficients of the second-order polynomial ( $\mathrm{a}, \mathrm{b}$, and $\mathrm{c}$; where $\mathrm{c}$ is the constant number) with least squares methods.

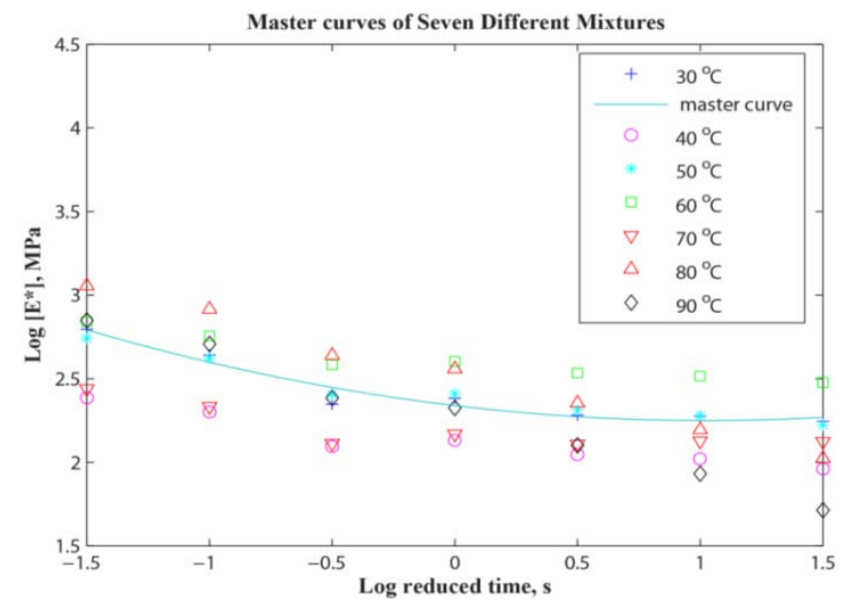

(a)

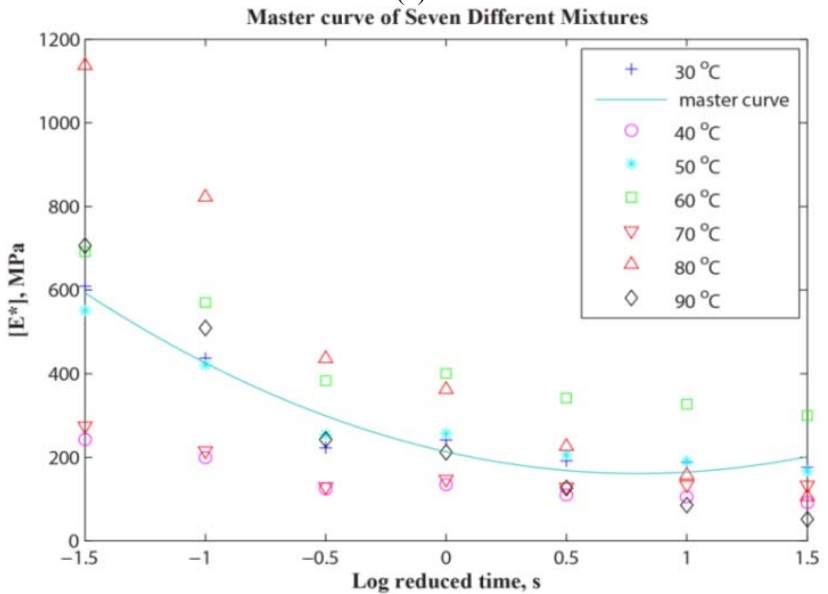

(b)

Fig. 5. (a) .(b) Fitted master curves of AC10 C320 MI B3; AC10 A10E M2 B4; AC10 A15E M3 B4; AC10 Multi600/170; AC10 A20E M6 B7; AC10 A15E (EVA) M7 B5; AC10 450 M10 B7.

Fitted master curves of AC10 C320 MI B3; AC10 A10E M2 B4; AC10 A15E M3 B4; AC10 Multi600/170; AC10 A20E M6 B7; AC10 A15E (EVA) M7 B5; AC10 450 M10 B7 are shown in Fig. 5. From the data demonstrated, it can be seen that all the asphalt mixtures have a similar patterns apart from Caption (a) is shown $\log \left|E^{*}\right|$ whereas Caption (b) is $\left|E^{*}\right| \mathrm{f}$ the fitted master curve. Asphalt mixtures have followed the linear range with the fitted master curve. These indicate the dynamic modulus master curves and shift factor 
are in good agreement. Garcia and Thompson [26] concluded that good agreement and similar accuracy dynamic modulus obtained from laboratory test. Similarly, Kim, Seo and Momen [27] also reported a good agreement and similar accuracy of dynamic modulus master curves, and shift factor are obtained from laboratory test.

\section{Effect of Loading Frequency and Temperature \\ 1) Loading frequency}

Loading frequency versus dynamic modulus $\left|E^{*}\right|$ s shown in Fig. 6. From the data presented in the figure, it can be been that the dynamic modulus $\left|E^{*}\right| \mathrm{f}$ the polymer modified mixture increase as the loading frequency increase. This shows that the dynamic modulus $\left|E^{*}\right| \mathrm{s}$ small at high temperature and low frequency. However, it can be increase under the contrary condition according the principle of time-temperature superposition. For example, take the dynamic modulus at reference temperature as shown in the figure; it is obvious that the dynamic modulus of the mixture increase with the increase of loading frequency.

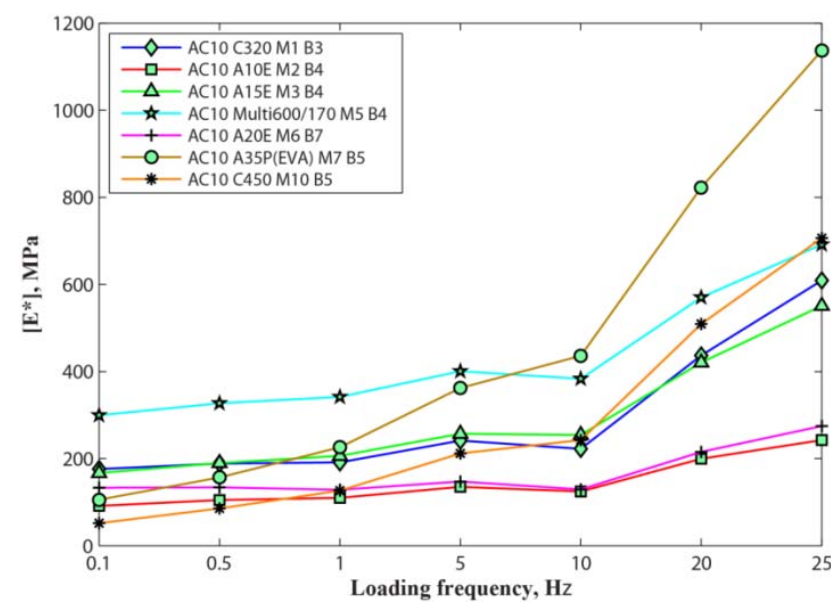

Fig. 6. Plot of loading frequency versus $\left|E^{*}\right|$.

\section{2) Temperature}

Temperature versus $\left|E^{*}\right|$ s shown in Fig. 7. From the data presented, it can be seen that mixes with AC10 A35P (EVA) modifier generally had high dynamic modulus of $1337 \mathrm{MPa}$. AC10 C450 M10 B5 and AC10 Multi 600/170 MB B4 modifiers were the second effective in performance of $\left|E^{*}\right| \mathrm{f}$ 706 and $691 \mathrm{MPa}$, respectively. These can be either lower or higher at the reduced time. This implies that the $\left|E^{*}\right|$ these two modifiers are closer to AC10 A35P (EVA) modifier according the principle of time-temperature superposition. For example, the dynamic modulus at loading frequency of 5 $\mathrm{Hz}$ that shows the increase in temperature will softened the asphalt binder, while the dynamic modulus $\left|E^{*}\right|$ s decreased.

The dynamic modulus at low temperature of $30{ }^{\circ} \mathrm{C}$ is about twice as high temperature of $90{ }^{\circ} \mathrm{C}$.

However, AC10 A10E M2 B4 and AC10 A20E M6 B7 modifiers had a very low of dynamic modulus. And this indicates the modifiers mixes might have exposed to rutting and then contribute low performance on structure. While AC10 A10E M2 B4 and AC10 A20E M6 B7 modifiers are intermediate modifiers to the principle of time-temperature superposition. Although the modifiers can be improved to rich the second level with a good aggregate asphalt mixes.

AC10 A35P (EVA), AC10 C450 M10 B5 and AC10 Multi $600 / 170$ MB B4 polymer modifiers extremely huge with their pavement performance compared to the other asphalt mix modifiers. Especially, when both are at high temperature, low frequency, and low reduced time, these three polymer modifiers including the two intermediate modifiers can strength and stable the mixture of stiffness, and also improved the rutting resistance pavement performance as mentioned on several literatures [2], [14], [24], [26], [28]-[31].

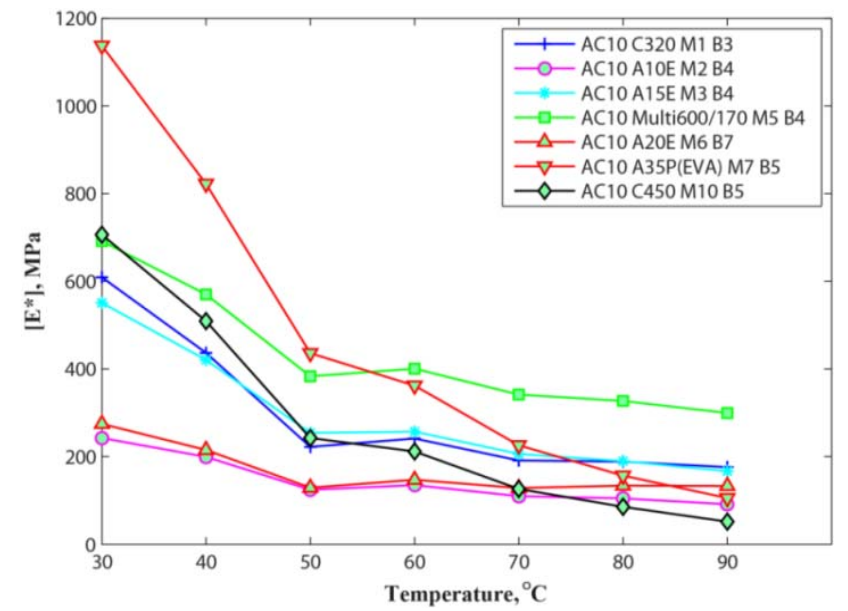

Fig. 7. Plot of temperature versus $\left|E^{*}\right|$.

\section{3) Binder viscosity - temperature susceptibility}

A summary of viscosity of binder and temperature susceptibility of asphalt mixtures are shown in Fig. 8 and Table V. The complex shear modulus $\left(G^{*}\right)$ of binder, viscosity $(\eta)$, A and VTS were concurrently solved using (10) to (13). From the data presented, it can be seen that a strong correlation between binder viscosity and temperature $\left[R^{2}=1\right]$ for polymer modified asphalt mixture. The stiffness modulus (at $2.82 T_{R}$ and $0.1 \mathrm{~Hz}$ ) ranging from 251 to 1038 $\mathrm{MPa}$ at phase angle of 60 degree, whereas binder ' $\mathrm{A}$ ' (intercept) parameter, $\mathrm{A}=-3.5617$ and the viscosity temperature susceptibility, VTS $=10.652$. Results shows increase in binder viscosity, and this larger increase in binder viscosity implies to reducing asphalt failure temperature and improved low-temperature cracking resistance with asphalt pavement [19], [32], [33]. Since temperature susceptibility of asphalt is independent of the rate of cooling, it is deduced that failure occurs when the asphalt mixture attains a critical physical rate.

The Connecticut Department of Transportation (CDOT) assessed the modulus, $E^{*}$, as a test method to characterize hot-mix asphalt mix design as the part of 2002 Pavement Design Guide. Results has shown a good correlation $\left[R^{2}=\right.$ 0.9997 ] between binder viscosity -temperature [3]. Similarly, Rasmussen, Lytton and Chang [19] has plotted VTS and found a $\left[R^{2}=0.999\right] .\left[R^{2}=1\right]$ between binder viscosity and temperature for asphalt mixture. 
TABLE V: BINDER DATA (VISCOSITY -TEMPERATURE RELATIONSHIP)

\begin{tabular}{|l|l|l|l|l|l|l|l|}
\hline $\begin{array}{l}\text { Temperature } \\
\left({ }^{\circ} \mathrm{C}\right)\end{array}$ & $\begin{array}{l}\mathrm{E}^{*} \\
(\mathrm{MPa})\end{array}$ & $\begin{array}{l}\text { G* } \\
(\mathrm{MPa})\end{array}$ & $\delta$ & $\begin{array}{l}\text { Temperature } \\
\text { (Rankine) }\end{array}$ & $\begin{array}{l}\text { Viscosity } \\
(\mathrm{cpoise})\end{array}$ & $\begin{array}{l}\text { Log Temperature } \\
(\text { Rankine })\end{array}$ & $\begin{array}{l}\text { Log Log Viscosity } \\
(\mathrm{cpoise})\end{array}$ \\
\hline 30 & 601.77 & 1037.53 & 60 & 545.67 & 208.82 & 2.74 \\
\hline 40 & 453.44 & 781.79 & 60 & 563.67 & 157.35 & 2.75 \\
\hline 50 & 256.02 & 441.41 & 60 & 581.67 & 88.84 & 2.76 & 0.90 \\
\hline 60 & 250.02 & 431.07 & 60 & 599.67 & 86.76 & 2.78 \\
\hline 70 & 189.92 & 342.92 & 60 & 617.67 & 69.03 & 2.79 & 0.81 \\
\hline 80 & 169.43 & 281.78 & 60 & 635.67 & 56.71 & 2.80 \\
\hline 90 & 146.26 & 251.17 & 60 & 653.67 & 50.55 & 2.82 \\
\hline
\end{tabular}

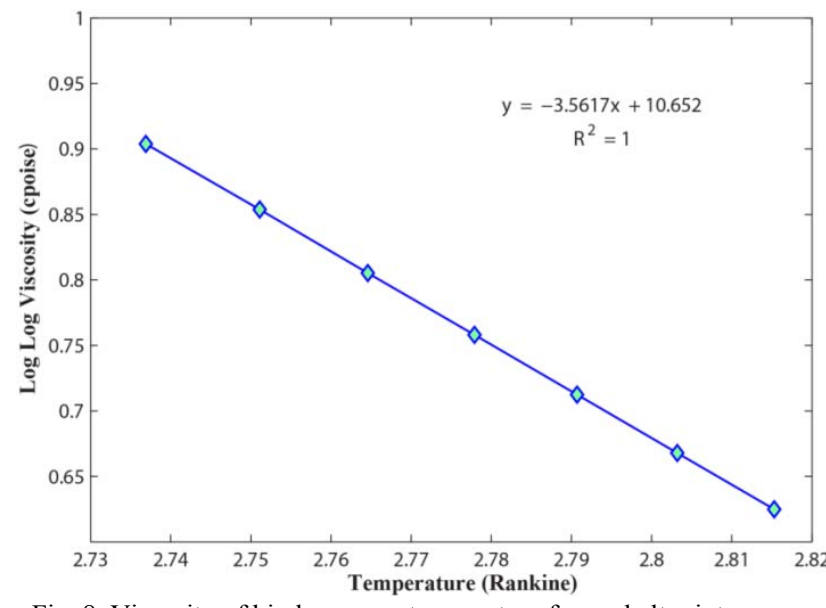

Fig. 8. Viscosity of binder versus temperature for asphalt mixtures.

\section{CONCLUSIONS}

All the asphalt polymers that are used in this research study can strength and stable the mixture stiffness of asphalt that is notable. The modification effect rank can be described as AC10 A35P (EVA) M7 B5 > AC10 450 M10 B5 > AC10 Multi 600/170 M5 B4 > AC10 C320 M1 B3 > AC10 A15E M3 B4 > AC10 A20E M6 B7 > AC10 A10E M2 B4 in this research.

$$
\text { The }\left|E^{*}\right| \mathrm{f} \text { AC10 A35P (EVA) M7 B5, AC10 } 450 \text { M10 B5 }
$$

and AC10 Multi 600/170 M5 B4 had been generally higher compare to the others polymer modifiers because there were mixes with aggregates, and for that matter, modifiers were functioned at high temperature and at low frequency which reduced time loading.

The good correlation $\left(R^{2}=1\right)$ for all the modifiers proved that the laboratory testing using various temperature can improved the rutting resistance. Dynamic modulus can be obtained as nearly as identical to the laboratory result using master curves and good correlation between the $\left|E^{*}\right|$ and the shifted factor as the function of temperature and time. In general, the predicting mixture performance of dynamic modulus using laboratory test with various temperature can improved the rutting and fatigue resistance of the pavement structure.

\section{ACKNOWLEDGEMENT}

The financial support for this study was provided by the research project 2011/0006, entitled "Characteristics of Western Australia Asphalt Mixes" sponsored by Australia Postgraduate Awards (APA), Curtin Research Scholarship (CRS), the Mainroads Western Australia and Fulton Hogan.
The options, findings and conclusions expressed in this publication are not necessary those of Australia Postgraduate Awards, Curtin Research Scholarship, Mainroads Western Australia or Fulton Hogan.

\section{REFERENCES}

[1] National Cooperative Highway Research Program, "Guide for mechanistic-empirical design of new and rehabilated pavement structures," Transportation Research Board National Research Council, Champaign, Illinois, USA.,March 2001.

[2] National Cooperative Highway Research Program, "Development of the 2002 guide for the design of new and rehabilitated pavement structure: Phase II," Transportation Research Board, Washington, D.C. USA. NCHRP Project I - 37A, February 2004.

[3] C. E. Dougan, J. E. Stephens, J. Mahoney, and G. Hansen, "E* dynamic modulus test protocol - problems and solutions," Connecticut Transportation Institue, University of Connecticut, Storrs, Connecticut, USA Report Number CT-SPR-0003084-F-03-3, pp. 1-30, 2003.

[4] A. Bayat, H. A. Kasani, and H. R. Soleymani, "Investigation of temperature dependency of asphalt concrete using laboratory dynamic modulus and field deflection testing," Transporation Research Board, Washington, DC. TRB 2011 Annual Meeting, pp. 1-13, January 2011.

[5] W. A. Zeiada, K. E. Kaloush, K. P. Biligiri, J. X. Reed, and J. J. Stempihar, "Significance of confined dynamic modulus laboratory testing for conventional, gap and open graded asphalt concrete mixtures, TRB 2011 Annual Meeting," Transportation Research Board, Washington, DC., USA TRB 2011 Annual Meeting, pp.9-19, 2011.

[6] H. Azari, G. A. Khateeb, A. Shenoy, and N. H. Gibson, "Comparison of simple performance test $\left(\mathrm{E}^{*}\right)$ of accelerated loading facility mixtures and prediction (E*): use of NCHRP 1-37A and Witczak's new equations," Transportation Research Record: Journal of the Transportation Research Board, vol. 1998, pp. 1-9, 2007.

[7] B. Birgisson, G. Sholar, and R. Roque, "Evaluation of a predicted dynamic modulus for Florida mixtures," Transportation Research Record: Journal of the Transportation Research Board, vol. 1929, pp. 200-207, 2005.

[8] D. Singh, M. Zaman, and S. Commuri, "Evaluation of predictive models for estimating dynamic modulus of hot-mix asphalt in Oklahoma," Transportation Research Record: Journal of the Transportation Research Board, vol. 2210, pp. 57-72., 2011.

[9] G. Al-Khateeb, A. Shenoy, N. Gibson, and T. Harman, "A new simplistic model for dynamic modulus predictions of asphalt paving mixtures," Journal of the Association of Asphalt Paving Technologist, vol. 75E, pp. 1-40, 2006.

[10] D. Andrei, M. W. Witczak, and M. W. Mirza, "Development of a revised predictive model for the dynamic (complex) modulus of asphalt mixtures, NCHRP 1-37A, an interim report," University of Maryland, College Park, MD NCHRP 1-37, an Interim Report, March 1999.

[11] D. W. C. Jr, "Sensitivity evaluation of field shear test using improved protocol and indirect tension strength test prepared," Advanced Asphalt Technologies, LLC State College, Pennsylvania NCHRP Web Document 56 (Project 9-18[1]): Contractor's Final Report, June 2003.

[12] A. Loulizi, G. W. Flintsch, and K. K. McGhee, "Determination of in-place hot-mix asphalt layer modulus for rehabilitation projects by a mechanistic-empirical procedure," Transportation Research Record: Journal of the Transportation Research Board, vol. 2037, pp. 53-62, 2007.

[13] N. H. Tran and K. D. Hall, "Evaluating the predictive equation in determining dynamic moduli of typical asphalt mixtures used in Arkansas," Journal of the Association Asphalt Paving Technologists, vol. 74, pp. 1-17, 2005. 
[14] C. W. Schwartz, "Implementation of the NCHRP 1-37A design guide," Department of Civil and Environmental Engineering, University of Maryland, USA UMD FRS No. 430572, February 2007.

[15] C. W. Schwartz and R. L. Carvalho, "Implementation of the NCHRP 1-37A Design Guide final report Volume 2: Evaluation of mechanistic-empirical design procedure," Department of Civil and Environmental Engineering, The University of Maryland, Maryland, USA. UMD FRS No. 430572, February 2007.

[16] M. W. Witczak, D. Andrei, and W. N. Houston, "Guide for mechanistic-empirical design of new and rehabilitated pavement structures," Transportation Research Board of the National Research Council, Champaign, Illinois NCHRP Appendix DD-1, pp. 1-91, 2000.

[17] V. P. Puzinauskas, "Evaluation of properties of asphalt cements with emphasis on consistencies at low temperatures," in Proc. the Association of Asphalt Paving Technologists, Journal of Association Asphalt Paving Technologists, vol. 36, pp. 489-540, 1967.

[18] F. L. Roberts, P. S. Kandal, E. R. Brown, D. Lee, and T. W. Kennedy, Hot Mix Asphalt Materials, Mixture Design and Contruction, 2nd ed. Lanham, Maryland, USA: NAPA Research and Education Foundation, 1996.

[19] R. O. Rasmussen, R. L. Lytton, and G. K. Chang, "Method to Predict Temperature Susceptibility of an Asphalt Binder," Journal of Materials in Civil Engineering, vol. 14, pp. 246-252, 2002.

[20] O. S. Fonseca and M. W. Witczak, "A predictioin methodology for the dynamic modulus of in-place aged asphalt mixtures (with discussion)," Journal of the Association Asphalt Paving Technologists, vol. 65, pp. 532-572, 1996.

[21] American Concrete Institute Committee, "Aggregates for concrete," American Concrete Institute, Farmington Hills, MI, USA., ACI Education Bulletin E1-07, August 2007.

[22] E. R. Brown, P. S. Kandhal, and J. Zhang, "Performance testing for hot-mix asphalt," in Transportation Research Circular E-C068: New Simple Performance Tests for Asphalt Mixes, C. Cullather, J. Correro, J. Weeks, and J. Awan, Eds., ed Washington, DC: Transportation Research Board, 2004, pp. 85-106.

[23] Main Roads Western Australia, "Annual Report," Main Road Western Australia, Perth, WA, Australia,July 2007.

[24] H. Zhu, L. Sun, J. Yang, Z. Chen, and W. Gu, "Developing master curves and predicting dynamic modulus of polymer-modified asphalt mixtures," Journal of Materials in Civil Engineering, vol. 23, pp. $131-137,2011$

[25] T. K. Pellinen and M. W. Witczak, "Use of stiffness of hot-mix asphalt as a simple performance test," Transportation Research Record: Journal of the Transportation Research Board, 2002, pp. 80-90.

[26] G. Garcia and M. Thompson, "HMA dynamic modulus predictive models-a review," Illinois Center for Transportation, Department of Civil and Environmental Engineering, University of Illinois, Urbana, IL, Project Report 2002-2006 FHWA-ICT-07-005, January 2007.

[27] Y. R. Kim, Y. Seo, M. King, and M. Momen, "Dynamic modulus testing of asphalt concrete in indirect tension mode," Transportation Research Record: Journal of the Transportation Research Board, vol. 1891, pp. 163-173, 2004.

[28] A. K. Apeagyei, "Correlating rutting with dynamic modulus of asphalt concrete," Proceedings of the Institution of Civil Engineers, vol. 164, pp. 241-249, 2011.
[29] K. Mollenhauer, M. Wistuba, and R. Rabe, "Loading frequency and fatigue: In situ conditions \& impact on test results," Workshop on Four Point Bending, Pais, Ed., ed Germany: University of Minho, 2009, pp. 261-276.

[30] C. W. Schwartz, "Evaluation of the Witczak dynamic modulus prediction model," in Proc. the 84th Annual Meeting of the Transportation Research Board, Washington, D.C., 9-13 January 2005. [CD-ROM], Washington, D.C, 2005.

[31] M. W. Witczak and J. Bari, "Development of a master curve (E*) database for lime modified asphaltic mixtures," Department of Civil and Environmental Engineering, Arizona State University, Tempe, Arizona, July 2004.

[32] T. R. J. Fabb, "The influence of mix compaction, binder properties and cooling rate on asphalt cracking at low temperatures," in Proc. Association Asphalt Paving Technologists, Minnesota, 1974, pp. 285-331

[33] L. H. Lewandowski, "Polymer modification of paving asphalt binders," Rubber Chemistry and Technology, vol. 67, pp. 447-480, 1994.

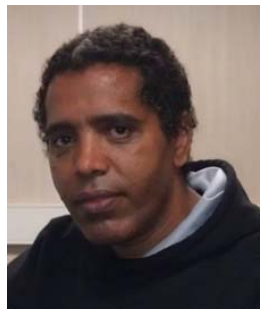

Ainalem Nega is currently a $\mathrm{PhD}$ Candidate at Department of Civil Engineering, Curtin University in Perth, Australia. He is under supervision of Professor Hamid Nikraz and Professor Imad L. Al-Qadi. He has a MEngSc. -research degree in hydrology 2011)from the University of Western Australia. He also holds a BEng. in mining and environmental Engineering degree from the Western Australia School of Mines, Curtin University of Technology (2007).

$\mathrm{He}$ is currently working as a lecturer at Curtin University in Perth, Australia while he is also studies his $\mathrm{PhD}$ in civil engineering. He was a lecturer at Western Australia School of Mines (WASM) in 2011 and was involved in casual academic teaching and Tutoring at the University of Western Australia since 2008 till his MEngSc.-research degree finished in 2011. He had also worked with SGS Lakefield Oretest Pty.Ltd, Operating Uranium Pilot Plant and Kimberley Diamond Company (Vacation Student Employment) in Australia in 2011 and 2006, respectively and other NGO's such as UNHER, LWF and Norwegian Save the Children as Supervisor in Kenya. He has published 11 papers in refereed journals articles and international conferences proceedings in the area of pavement materials engineering and pavement numerical modelling.

His research interests are focused on civil engineering and pavement materials, highway and airfield pavement mechanics, advance modeling including viscoelastic respond to the traffic loading, pavement design, pavement fracture, assess pavement performance, engineering pavement management systems, pavement condition assessment and modeling of pavement interface and layer.

Mr. Nega is a member of International Society for Asphalt Pavement (ISAP), member of graduate Western Australia School of Mines (GWASM) and Australasian Institute of Mining and Metallurgy (GAusIMM). He got an Australia Postgraduate Award (APA) Scholarships and Curtin Reseach Scholarships (CRS) (Top UP) for PhD-Research degree in 2012 and University Postgraduate Awards (UPA) Scholarship and UWA Top Up for MEngSc-Research degree in 2008 from the University of Western Australia. 